\title{
Reflections of academic nurse leaders on transformational leadership styles utilised in nursing education institutions, South Africa
}

\author{
Sipho W. Mkhize* \\ School of Nursing and Public Health, College of Health Sciences, University of KwaZulu Natal, Durban, South Africa
}

Received: November 28, 2018

DOI: $10.5430 /$ jnep.v9n10p92

\author{
Accepted: May 15, 2019 \\ Online Published: July 28, 2019 \\ URL: https://doi.org/10.5430/jnep.v9n10p92
}

\begin{abstract}
Objective: The aim of this article is to reflect on the experiences of the nursing education leaders with transformational leadership styles, with the objective of describing such styles used by academic nurse leaders.

Methods: The qualitative research adopted an explorative, descriptive and contextual design. The participants $(\mathrm{N}=8)$ were purposively selected, based on their availability and number of years' experience as nursing education leaders, through an open invitation. Data was collected by means of in-depth individual interviews using a broad, central question, thereby allowing the participants to interpret the question and answer voluntarily. All tape-recorded interviews and field notes were transcribed verbatim and analysed using open coding of Tesch to identify themes and sub-themes.

Results: The results reflected transformation was viewed differently by participants, and as challenging and inclusive. Participants reported that transformation was challenging due to the number of demands from policy makers for the implementation of unified curriculum reforms, which were student-centred, restructuring and rationalisation of fragmented nursing education institutions (NEIS) to one college (leadership and governance) and campuses (teaching and learning) per province in South Africa. Participants also reflected there were inadequate human and material resources supporting the implementation of policy directives. Participants revealed the transformation was inclusive, and the new policy framework for unified and seamless national education system should be adopted and implemented across all levels. The noticeable shared leadership was perceived as inclusive transformation. Participants verbalised that transformation made strides to ensure that integration of all categories of staff. Participants voiced strong views that team functioning, with a common goal to achieve transformation, was the vehicle for the success of nursing education institutions.

Conclusions: The research revealed that transformational leadership was experienced differently by academic nurse leaders. These different views created awareness to review existing strategies in the implementation of transformation. Academic nurse leaders should explore alternative approaches to ensure transformation is fully embraced and hurdles are addressed collectively. The monitoring and evaluation of the transformation process is a recipe for a successful transformational leadership style.
\end{abstract}

Key Words: Academic nurse leader, Nursing education institution, Transformational leader, Transformational leadership, Transformational leadership style, Rationalisation

\section{INTRODUCTION}

The birth of a democratically elected government in South Africa prompted changes in all spheres of government. The education landscape had to change in order to focus on addressing inequality and imbalances that existed during the apartheid system. The new government promulgated leg-

\footnotetext{
*Correspondence: Sipho W. Mkhize; Email: mkhizes4@ukzn.ac.za; Address: School of Nursing and Public Health, Howard College Campus, Private Bag x54001, Durban, 4000, South Africa.
} 
islation to guide the transformation, and policy guidelines were formulated to facilitate implementation of transformation. ${ }^{[1,2]} \mathrm{Ngcamu}^{[3]}$ posits that the transition from the previous regime was a mammoth task to restructure and redefine the education system to achieve the equality and quality for all South African citizens. The rationalisation of nursing education institutions received much attention to root out fragmentation that existed in all nine provinces of South Africa. This culminated in nursing education institutions merging to form administrative colleges (leadership and governance) and campuses (teaching and learning) for uniform functioning. The mergers brought about challenges and instability amongst academic nurse leaders who were in charge of "colleges" in the various towns and cities within provinces, as relegation to a campus status impacted on autonomy and restructuring operations. ${ }^{[4]}$

The success of transformation is influenced by the leadership style, which fosters change from transactional to transformational leadership. Alzawahreh ${ }^{[5]}$ described transformational leadership as the process that changes and transforms individuals and organisations, motivates people for change, improves on leadership and service delivery and also involves assessing associates' motives, satisfying and valuing their needs. ${ }^{[6]}$ Northouse ${ }^{[7]}$ asserts that transformational leadership, through its incorporation of "charismatic and visionary leadership," can look to influence rather than change within organisations. According to Smith, ${ }^{[8]}$ transformational leadership style recognises of areas in which change is required and inspire followers by creating a sense of commitment. Bass $^{[9]}$ asserts that a model of transformational leadership uses behaviours of idealised influence, inspirational motivation, intellectual stimulation, and individualised consideration, to motivate followers and to achieve higher levels of performance. Bennis and Nanus, as well as Northouse, ${ }^{[7]}$ perceived the transformational leader as someone who plays an important function in precipitating change, whereby followers and leaders are inextricably bound together in the transformation process and help transform organisations through clear vision, social architects, creating trust and creative deployment of self.

The institutional restructuring of higher education and a new landscape intended to provide an equitable, sustainable and productive higher education system of high quality and contribute effectively and efficiently to the human resources, skills, knowledge and research needs of South Africa. ${ }^{[1]}$ The implementation of a rationalisation programme for nursing education institutions has left the current nursing education leaders disempowered to manage and lead the nursing education institutions successfully. The change in responsibilities, environment and expectations of nursing education leaders, without proper mechanisms and processes to support them in keeping up with the changes, creates a performance gap that can be addressed through recommendations based on the findings of this study.

\section{METHOD}

\subsection{Design}

The research was qualitative in nature and adopted an exploratory, descriptive, contextual design. ${ }^{[10]}$ In this study, the researcher applied a qualitative approach that focused on processes rather than outcomes, as the participants described and interpreted the subjective, meaningful world of transformational leadership. An exploratory design was chosen to determine whether the phenomenon had deeper meaning, and to explore a relatively unknown territory in order to gain new insight on the phenomenon rather than evaluating it. The descriptive design was adopted to describe the social setting of investigation, making it less complicated, to gain understanding and insight for the researcher. The objective was to present an accurate description of what was being studied. The context was used by conducting interviews in the natural setting whereby participants are familiar with the setting to express their views and experiencing freely.

\subsection{Ethical considerations}

The ethical clearance was approved and obtained from the North West University Ethics Research Committee and from four (4) Provincial Departments of Health Ethics and Research Committees. The researcher ensured clarity regarding the nature of the study, protection of individual participant identity, participant role in the study, the objective and purpose of the research and whom the study aimed to benefit. The researcher assured the participants' roles were voluntary and that withdrawal could take place at any time with no repercussions. In order that data obtained could not be traced back to participants, pseudonyms were used to ensure confidentiality. The permission to use an audio tape recorder during interviews was obtained from participants, and it was explained to them that the research data would be stored and managed in alignment with the following legislative frameworks. The research data will kept for 5 years and deleted thereafter, according to the University's policy on storage and management of research data.

\subsection{Sampling and data collection 2.3.1 Population}

The participants (academic nurse leaders) were drawn from four (4) Nursing Colleges in Gauteng (two campuses), Free State (one campus), Kwa-Zulu Natal (four campuses) and North West (one campus). The participants $(\mathrm{N}=8)$ were purposely selected, based on their availability and number 
of years' experience as nursing education leaders, through an open email invitation. Purposive sampling was adopted, based on the assumption that the researcher wanted to discover, understand and gain insight. ${ }^{[11]}$ According to Sutton and Austin, ${ }^{[11]}$ choosing a sample allows the researcher to select participants because they pose a feature or process in which the researcher is interested and they meet the sampling criteria for inclusion. The logic and power of purposive sampling lies in selecting rich information cases from which one can learn a great deal about issues that are important to the purpose of the research.

\subsubsection{Sampling criteria}

The inclusion criteria were:

- Registered nurse educators and nurse administrators with the South African Nursing Council.

- Employed and permanent as academic nurse leaders of the nursing education institution.

- A minimum of three years and above in the position of academic nurse leader.

- Communicated in English.

\subsubsection{Sample size}

The size of the sample was determined by the saturation and number of the data collection methods. According to Morse $^{[12]}$ and Kim et al., ${ }^{[13]}$ data saturation is adequate and operationalised until no new information is obtained; when a cohesive sample is selected that shares the characteristics that address the research topic. In this research, eight (8) participants were interviewed for 60 minutes until no new information came forth.

\subsection{Data collection}

The data was collected by in-depth individual interviews using and a broad, central question, "What are your lived experiences of transformational leadership in the nursing education institution?" allowing the participant to interpret the question and answer voluntarily. The participants were to describe their emic perspective with regard to their experiences with transformational leadership in the nursing education institutions. The researcher sought to interpret the meaning of central themes, registering and interpreting the meaning of what is said, as well as how it is said. Field notes were taken as a method of remembering observations during individual interviews, retrieving and analysing these observations. The field notes were purposefully left unedited in their original state to prevent bias during verbatim transcription. The interviews were conducted in a boardroom, which was situated in private area where there were no distractions, easily accessible for participants to attend. The interviews were conducted in English and an audio-tape recorder was used to capture the rich data as described by participants. All participants were asked the same open-ended question at the beginning, thereafter communication skills and interview techniques were utilised, which included active listening, silence, questioning, restating, reflecting, paraphrasing and clarifying. ${ }^{[14]}$ Bracketing, putting preconceived ideas aside, and intuition were used during the interview. ${ }^{[15]}$ Data were collected for four months, from September 2015 to December 2015. Kvale ${ }^{[16]}$ stated that in-depth research employs open-ended questions to understand the experiences as described and experienced by participants, and the manner in which these experiences are presented. Kvale ${ }^{[16]}$ explained the purpose of an interview as being to obtain "open nuanced" description of the lived world of the interviewees with respect to interpretations of the described phenomena.

\subsection{Data analysis}

All interviews, including recorded information and field notes, were transcribed verbatim. The data was read and reread, then manually analysed using open coding of Tesch ${ }^{[17]}$ to identify themes and sub-themes. The data, coded by the researcher, was co-coded and verified by an independent coder. The discrepancies between the researcher and independent coder were discussed until unambiguous themes and subthemes were agreed upon and consensus reached. ${ }^{[17]}$ The database of participants' transcripts, compiled and saved on a computer, were protected by a password known only by the researcher.

\subsection{Trustworthiness}

Rigour was ensured by using the model of Lincoln and $\mathrm{Guba}^{[18,19]}$ to assess the trustworthiness of the qualitative data. The criteria of credibility, transferability, dependability and confirmability were strategically applied to assess the value of the findings and trustworthiness of the study.

Credibility establishes whether the research findings represent plausible information drawn from the participants original data and is a correct interpretation of the participants original views. ${ }^{[2]}$ The researcher focused on the following aspects:

Prolonged engagement: All questions regarding the research were answered before the central question was asked. During the interview process, the research to support and learn from the participants' experiences,

Reflectivity journal: The researcher kept a journal in which all experiences and observations were recorded during for data collection process. It covered objective and subjective information the use of metaphors, non-verbal cues, postures of participants. 
Triangulation: The process of data collection involved in depth interview, reflective journal, field notes and observations during the interview process. The researcher and independent coder held meetings and discussed data analysis in order to reach a consensus.

Member checking: The researcher met with participants and presented to them the findings in order to check whether these reflect what they have meant in the interviews. It was done to strengthen the data especially because the researcher and participants look at data differently.

Transferability the degree to which results of qualitative research can be transferred to other contexts or settings with other participants. ${ }^{[2]}$ The researcher used purposive sampling, whereby the participants had experience in leadership and in depth knowledge, communication skills and interview techniques, dense description about the context, participants and methodology. A dense, thick description of results was supported by direct quotations of participants.

Adaptability refers to the constancy of the data over time and under different conditions. ${ }^{[2]}$ The researcher used 'step-wise' replication of research methods: code-recode, recording of data and dependability audit, where an in-depth interview allowed participants to describe their emic perspectives while audiotape recordings and field notes were taken to enrich data. The detailed description of the methodology made the study repeatable.

Confirmability refers to the researcher's ability to demonstrate the aspect of neutrality that the data represents the participants' responses and not the researcher's biases or viewpoints and to secure inter-subjectivity [2]. The researcher used a confirmability audit of the research process, where transcriptions and field notes were available for auditing and destroyed once the research was completed five (5) years later, according to the University's policy on storage and data management.

\section{Results}

Participants comprised of seven females and one male, ranging from 40 to 60 years (average age of 50 years). Years of experience ranged from 6 years to 33 years. Two themes emerged from the research, namely transformation is challenging, and transformation is inclusive.

\subsection{Theme one: Transformation is challenging}

In this research, the theme "transformation is a challenge" refers to transformation demands that require sophisticated and uncompromising execution of transformation agenda of the government. Participants viewed transformation as a challenge because it was a directive from the policy makers

Published by Sciedu Press that must be implemented for recruitment and selection of students to address equity, curriculum reforms, and manage institutions effectively within the limited resources. These reflections were evidenced by the following quotations:

"The whole system of department of health, senior managers to have no vision of nursing education. There are less interested and lacking information about nursing education." (A002) "There is a national mandate for colleges to increase intake; unfortunately politicians see numbers not quality." (A004)

Another participant echoed,

"With increase number of students, they don't look at resources. Resources are insufficient especially human and transport" (A002).

A response from a participant highlighted

"There is insufficient budget to address the demands coming from highest authorities" (A007) "There is so much red tape in releasing funds in order to purchase material resources required to execute teaching and learning" (A005).

Another response viewed the challenge with regard to standards and compromised quality,

"Quality has impacted. We are dictated not to take cream of the crop, middle and low, that impacts our teaching. Teaching is disturbed." (A007).

"With transformational leadership it took quite some time for people to develop in terms of participating and contributing and development in nursing education. The way I see transformation and personal experience is that lecturing staff had a lot of dependency to provide answers." (A009)

Participants reported that this challenge negatively affected some lecturers, as they were loath to transform due the number of years in academia. Lecturers only believed in expertise, which is a mismatch with current dispensation and lacked innovation.

This was supported by the following quotations:

"My past experience, the way I see transformation and personal experience is that lecturing staff had a lot of dependency to what they acquired many years ago. (A005, A003, A007) 
"Nurse educators just they tend to be narrow, hence there is not a need to search for information, in terms of education where do we actually fit in whether we are in with changes that are occurring."(A005)

\subsection{Theme: Transformation is inclusive}

This theme, "transformation is inclusive", refers to different levels of responsibility of academic nurse leaders to address transformation through transformation leadership style. Participants felt that shared leadership in the context of transformation is noticeable. Participants had strong views that team functioning was the vehicle for the success of nursing education institutions to achieve transformation.

The reflection was supported by the following quotations:

"What I have observed, is that, we know that we are here for a common goal our product is equipped with skills, actualise the vision of the Department." (A001)

"And again working with them when they come in an atmosphere of trust they will their give valuable contribution." (A005)

Participants reflected that dual communication and responsiveness to both parties is indicative of inclusiveness:

"I use an open door type of consultation. I believe that I have to trust people with their responsibilities various roles. I try to have open feedback." (A005)

"I communicate with Clinical Nursing Management who provide with clinical nursing practice". (A004)

The participants expressed that good communication with other management and subordinates was a vehicle management of operations and processes. They felt communication was the mutual exchange of ideas and interpretation of messages. They also added that this mutual exchange of ideas and interpretations of messages were not only the basis of all forms of communications, but also the root of man's existence.

The reflections are evidenced by the following quotations:

"I make it my priority and responsibility that I keep them informed the nursing manager, assistant managers in human resources and operational managers in the units where most of professional socialisation takes place.(A003)" "I use an open door type of consultation. I believe that I have to trust people with their responsibilities various roles. (A009)
The participants saw inclusive transformation as a step in the right direction, and working as team promoted cohesiveness within nursing education institutions.

Sentiments echoed by participants were:

"I have been a principal since 2001. As part of transformation, the college management has decided to include Student Representative Council in all committees and meetings." (A001)

"All stakeholders are involved the College Council and SRC even when we discuss the budget." (A002)

"Whenever the student relates the decision has to be taken, the SRC is involved and that is a very big step transforming." (A004)

"Inclusion of SRC, we minimise any confrontation and discomfort." (A010)

\section{Discussion}

The objective of the study was to describe the transformational leadership styles used by academic nurse leaders. Transformation, which is challenging and inclusive for leadership were discussed with literature control to support the findings of the study.

\subsection{Transformation is challenging}

The study revealed that the challenge of transformation implementation was due to its uniqueness in the South African context, as driven by political agenda of transformation, redress and equity. However, Jansen ${ }^{[20]}$ criticised the South African government of 'political symbolism' in terms of its educational reform because it does not discount the possibility that education policies have resulted in some degrees of positive changes with the higher education system. Harber et al. ${ }^{[21,22]}$ concurred with Jansen ${ }^{[20]}$ that there were contextual factors specific to South Africa shaping teacher resistance to democratic reform.

Schultz ${ }^{[23]}$ echoed that mergers have been a major and highly contested theme in higher education in the South African context, being a political decision, which must be implemented. The transformation agenda to be achieved in South Africa has been based on compliance to government only, with inconspicuous impact on institutions, faculties, departments and individuals. Davis et al. ${ }^{[2]}$ argued that higher education institutions (HEIs) did not adapt to changes as fast as those that occurred in the environment, and postulated that collegial governance is dominated by traditional academic structures and practices (aligned with guild-like interest) that led to the creation of irrationalities and inefficiencies in the system and its institutions subordinates. A publication of the 
Centre for Higher Education Transformation (CHET) ${ }^{[25]}$ affirmed that on leading change and managing transformation in higher education, managers face challenges to implement the strategic issues stipulated by the policy, whilst needing to accustom themselves with requirements.

Badat ${ }^{[26]}$ illustrated that the transformation agenda in higher education embodies paradoxes, to pursue simultaneously a number of values and goals that are in tension with one another. The paradoxes raise social and political dilemmas, difficult choices and the question of possible trade-offs between values, goals and strategies. Scott ${ }^{[27]}$ suggested an alternative that higher education needs excellent leadership at all levels of the organisation in order to remain competitive.

Badat ${ }^{[26]}$ viewed the exacerbation of the challenges that are due to the inadequacy of public funding of transformation development programmes of academic staff and student academic development. In addressing this challenge, Scott ${ }^{[27]}$ concluded that systemic responses are essential for improving the educational outcomes to reform core curriculum frameworks; enhancing the status of teaching and building educational expertise. In contrast, Leithwood and Jantzi ${ }^{[28]}$ argued that in the case of England's National Literacy and Numeracy Strategies (NLNS), and provide serious incentives and sanctions for compliance.

Yadav and Agrawal ${ }^{[29]}$ recommended that transformational leaders must empower followers to achieve change and motivate them during tough times to deal with resistance, which is inevitable. Transformational leaders must overcome this resistance, by working harder to get the dissenters on board.

The remedy to address challenges of transformation to be implemented can be learnt from Millar ${ }^{[30]}$ who stated leaders have to be effective change agents. The researcher proposes that academic nurse leaders should be able to understand various dimensions of transformation and prioritise accordingly. The success of change strategy of transformational leaders is dependent upon leaders' understanding of complexities and nuances associated with the pattern of climate perceived in nursing education institutions. Good leadership is about handling the essential differences in a manner that facilitates quality care with good housekeeping. Lack of clarity will damage any leadership strategy and leadership can become fractured and uncertain. Nursing education leaders have a responsibility to create change and transformation in their nursing colleges.

\subsection{Transformation is inclusive}

Inclusive transformation is strengthened by transformational leadership qualities of integrity, courage and passion, trust- worthiness, consideration, responsiveness and adaptability. Ryan $^{[31]}$ testified that inclusive leadership consists of a number of distinct practices that include educating participants, developing critical consciousness, nurturing dialogue, emphasizing student learning and classroom practice. Leithwood et al. ${ }^{[32]}$ concurs that leadership processes, which are inclusive they need to be organized to advocate for and cultural solidarity when they express cultural solidarity with their students.

Transformational leaders who convey a strong sense of purpose and collective mission, motivate followers by communicating inspirational vision to promote high performance among followers. ${ }^{[33,34]}$ Thus, transformational leaders often closely interact with their followers to better understand and address their needs. ${ }^{[35]}$

The rise of student engagement as a strategic construct for institutional assessment, accountability, and improvement efforts has been a consistent theme in higher education over the last decade. ${ }^{[36]}$ An emerging consensus in educational research is that student engagement is a critical goal for educational institutions. Steele and Fullagar ${ }^{[37]}$ agreed that if transformational leadership works similarly in classrooms as it does in organizations, one can expect that student outcomes will be similarly affected or influenced as are employee outcomes.

Academic leaders who are able to adapt and change, to envision alternative futures, to develop people and collaborative partnerships, to create a positive and collegial working atmosphere, being both supportive and able to get necessary support are able to influence others positively. ${ }^{[38-41]}$ This notion of 'leader as model' aligns with Martin et al.'s ${ }^{[42]}$ findings in their study of the links between university subject coordinators' leadership and teachers' approach to teaching. The quest to develop an academic leader is mandatory, as confirmed by Debowski et al., ${ }^{[43]}$ who stated that leadership development for learning and teaching in universities is generally not well recognised, understood or supported, neither were specific programmes for particular leadership roles, such as Head of School, common.

Debowski et al. ${ }^{[43]}$ found Aziz et al. ${ }^{[44]} \& \mathrm{Montez}^{[45]}$ in their studies a comprehensive strategy for conducting a formal assessment of training needs for department chairs and school directors in the higher education. Debowski et al. ${ }^{[43]}$ and Yielder et al. ${ }^{[46]}$ concluded that these programmes inadequately addressed academic leadership needs. It is surprising that even developed countries with massive resources are lagging in the preparation of academic leaders. There were only $3 \%$ of over 2000 academic leaders surveyed in US national studies between 1990 and 2000 had received any type 
of leadership preparation. ${ }^{[47,48]}$

The positive strides on team functioning and collaboration among academic nurse leaders, lecturers and student body were palpable. The interdependence of managerial leadership and staff organisational commitment has been documented in literature from as early as the mid-1950's. ${ }^{[49-51]}$ Dugan et al. ${ }^{[52]}$ supported student involvement as the key to understanding student leadership and the amount of physical and psychological energy that the student devoted to the academic experience. Academic nurse leaders communicated that transformation facilitated them to grapple with diversity management within nursing education institutions. Transformational leaders create awareness in their followers' minds by means of values that can be shared among employees. ${ }^{[53]}$ Transformational leaders exhibit a management approach that is far removed from prejudices by caring for and being aware of diversity in the school.

Transformation brought some positive aspects because doors were opened in the career ladder. They were capacitated into the new world of management and interacted with other managers from various departments in strategic issues. Elrehail et al. ${ }^{[54]}$ affirmed that inclusion influences the accommodation of diverse needs and gives all the possibility of success, whatever the personal characteristics or social background.

Okçu ${ }^{[55]}$ concluded that leaders of learning organisations, such as universities and colleges, are "designers, teachers and stewards," hence, transformational leadership leaders are required in the enhancement of learning organisations. Transformational higher education leaders needed to make institutions perform beyond capacity in the 21 st century. A leader who is concerned with creating an image of mystery and separateness is not effective in building coalitions in higher education. In general academic leadership, Leithwood and Jantzi ${ }^{[56]}$ argued that leadership is expected to be expert and referent rather than legitimate, coercive or reward-oriented.

\subsection{Recommendations}

The participants recommended that academic nurse leaders be involved in policy formulation and implementation, strategic leadership and planning, leadership for good governance, people management and project management. It is also prudent that peer networking be strengthened through inter- and intra-collaboration by means of electronic and print media. It is also important that there is a uniform and standard key performance management agreement, or negotiated service delivery agreement, to ensure there is no imbalance in transforming nursing education and training in South Africa. Academic nurse leaders need to become innovative in addressing strategies in attainment of transformational leadership.

The key lessons from this research on effective change implementation in higher education need to be part of every orientation and development programme for learning and teaching leadership.

\section{Conclusion}

This research revealed that transformational leadership is experienced differently by academic nurse leaders. These different views created awareness to review existing strategies in the implementation of transformation. Academic nurse leaders need to explore alternative approaches to ensure that transformation is fully embraced and hurdles are addressed collectively. The monitoring and evaluation of the transformation process is a recipe for the successful transformational leadership style. The study brought about awareness of critical issues that are crucial in leadership of nursing education institutions.

\section{ACKNOWLEDGEMENTS}

The researcher would like to thank all the provincial Departments of Health for giving permission for the study to be conducted and for volunteered participants. This research was self-funded.

\section{Conflicts of Interest Disclosure}

The author declares there is no conflict of interest.

\section{REFERENCES}

[1] Education Do. Education White Paper 3: A programme for the transformation of higher education. Government Gazette. 1997; 386 : 18207.

[2] Polit DF, Beck CT. Nursing Research: Generating and Assessing Evidence for Nursing Practice. 9th ed. Philadephia: Wolter Kluwer/Lippincot Williams \& Wilkins; 2012.

[3] Ngcamu BS. Conceptualizing transformation in the post-merger and incorporation environment era: A case of the Durban Univer- sity of Technology. International Journal of Sociology and Social Policy. 2016; 36(5/6): 270-88. https ://doi.org/10.1108/IJSS P-04-2015-0037

[4] Ntsele N. The experiences of the nurse educators following the rationalization of nursing colleges in Gauteng: University of Johannesburg; 2008.

[5] Alzawahreh AA. Transformational leadership of superiors and creativity level among faculty members in Jordanian universities. Journal of Institutional Research South East Asia. 2011; 9(1): 125-32. 
[6] Northouse PG. Leadership: Theory and practice: Sage publications; 2015.

[7] Northouse PG. Leadership: Theory and practice: Sage publications; 2018.

[8] Smith MA. Are you a transformational leader? Nursing Management. 2011; 42(9): 44-50. PMid:21873847 https://doi.org/10.109 7/01. NUMA. $0000403279.04379 .6 \mathrm{a}$

[9] Bass BM. Two decades of research and development in transformational leadership. European Journal of Work and Organizational Psychology. 1999; 8(1): 9-32. https://doi.org/10.1080/1359 43299398410

[10] Polit D, Beck C. Nursing Research: Generating and Assessing Evidence for Nursing Practice. 10th ed. Philadephia: Wolters Kluwer; 2017.

[11] Sutton J, Austin Z. Qualitative research: data collection, analysis, and management. The Canadian Journal of Hospital Pharmacy. 2015; 68(3): 226. PMid:26157184 https://doi.org/10.4212/cjhp .v68i3.1456

[12] Morse JM. Determining sample size. Sage Publications Sage CA: Thousand Oaks, CA; 2000.

[13] Kim H, Sefcik JS, Bradway C. Characteristics of qualitative descriptive studies: a systematic review. Research in Nursing \& Health. 2017; 40(1): 23-42. PMid:27686751 https://doi.org/10.100 $2 /$ nur. 21768

[14] Keltner N, Schwecke LH, Boston CE. Psychiatric Nursing. 3rd ed. St. Louis: CV Mosby; 1999.

[15] Burns NA, Grove SK, Barcelo TI. Burns \& Grove's Understanding Nursing Research: Building an Evidence-based Practice. 2013.

[16] Kvale $S$. The psychoanalytic interview as inspiration for qualitative research. Qualitative research in psychology: Expanding perspectives in methodology and design. 2003; 275-97. https://doi .org/10 .1037/10595-014

[17] Elo S, Kääriäinen M, Kanste $O$, et al. Qualitative content analysis: A focus on trustworthiness. SAGE Open. 2014; 4(1). https : //doi.org/10.1177/2158244014522633

[18] Lincoln Y, Guba E. Naturalistic Inquiry. 1985.

[19] Shenton AK. Strategies for ensuring trustworthiness in qualitative research projects. Education for Information. 2004; 22(2): 63-75. https://doi .org/10.3233/EFI-2004-22201

[20] Jansen JD. Targeting education: The politics of performance and the prospects of 'Education for All'. International Journal of Educational Development. 2005; 25(4): 368-80. https://doi.org/10.1016/ j.ijedudev. 2005.04.009

[21] Harber C. Revolution, what revolution? Contextual issues in citizenship education in schools in England. Citizenship, Social and Economics Education. 2009; 8(1): 42-53. https://doi.org/10 $.2304 /$ csee. 2009.8 .1 .42

[22] Harber C, Mncube V. Is schooling good for the development of society?: the case of South Africa. 2011.

[23] Schultz H. Induction and Staffing decisions. In: Nel P, van Dyk P, Haasbroek G, Schultz H, Sono T, Werner A, editors. Human Resources Management. 6th ed. Cape Town: Oxford University Press South Africa; 2004; 250-66.

[24] Davis A, Jansen van Renburg M, Venter P. The impact of managerialism on the strtaegy work of university middle managers. Studies in Higher Education. 2016; 41(8): 1480-94. https ://doi .org/10.1 080/03075079.2014.981518

[25] Centre for Higher Education Transformation (CHET). Leading Change and Managing Transformation in Higher Education: Report on Workshops for Human Resource Practitioners 2001. Pretoria: Creda Communications; 2001.

Published by Sciedu Press
[26] Badat $\mathrm{S}$. The challenges of transformation in higher education and training institutions in South Africa. Development Bank of Southern Africa. 2010; 8: 1-37.

[27] Scott G, Coates H, Anderson M. Learning Leaders. 2008.

[28] Leithwood K, Jantzi D. Transformational school leadership for largescale reform: Effects on students, teachers, and their classroom practices. School Effectiveness and School Improvement. 2006; 17(2): 201-27. https://doi.org/10.1080/09243450600565829

[29] Yadav S, Agrawal V. Challenges Face by Transformational leader and suggestions to solve the challenges. International Journal of Research in IT and Management (IJRIM). 2017; 7(5): 34-43.

[30] Millar C, Hind P, Magala S. Sustainability and the need for change: organisational change and transformational vision. Journal of Organizational Change Management. 2012; 25(4): 489-500. https: //doi.org/10.1108/09534811211239272

[31] Ryan J. Inclusive Leadership and Social Justice for Schools. Leadership and Policy in Schools. 2006; 5(1): 3-17. https ://doi.org/ 10.1080/15700760500483995

[32] Leithwood K, Jantzi D, Rossanne S. Changing Leadership for Changing Times. Changing Education Series. Canada: Institute of Education Science; 1999.

[33] Jin Y. Emotional leadership as a key dimension of public relations leadership: A national survey of public relations leaders. Journal of Public Relations Research. 2010; 22(2): 159-81. https: //doi.org/10.1080/10627261003601622

[34] Jin S, Seo MG, Shapiro DL. Do happy leaders lead better? Affective and attitudinal antecedents of transformational leadership. The Leadership Quarterly. 2016; 27(1): 64-84. https ://doi.org/10.101 6/j.leaqua. 2015.09.002

[35] Otara A. The Academic dean and the challenges of meeting changing expectations in a competitive higher education environment in Africa. Journal of Higher Education in Africa/Revue de l'enseignement supérieur en Afrique. 2014; 12(1): 133-50.

[36] Kuh GD. The national survey of student engagement: Conceptual and empirical foundations. New Directions for Institutional Research. 2009; 2009(141): 5-20. https://doi.org/10.1002/ir.283

[37] Steele JP, Fullagar CJ. Facilitators and outcomes of student engagement in a college setting. The Journal of Psychology. 2009; 143(1): 5-27. PMid:19157070 https://doi .org/10.3200/JRLP.143.1 . 5-27

[38] Drew G. Balancing Academic Advancement with Business Effectiveness? 2006.

[39] Middlehurst R. Changing Internal Governance: A Discussion of Leadership Roles and Management Structures in UK Universities. Higher Education Quarterly. 2004; 951: 5224.

[40] Vilkinas T, Cartan G. The integrated competing values framework: its spatial configuration. Journal of Management Development. 2006; 25(6): 505-21. https://doi.org/10.1108/02621710610670 092

[41] Bryman A. Effective leadership in higher education: A literature review. Studies in Higher Education. 2007; 32(6): 693-710. https://doi.org/10.1080/03075070701685114

[42] Martin E, Trigwell K, Prosser M, et al. Variation in the experience of leadership of teaching in higher education. Studies in higher Education. 2003; 28(3): 247-59. https://doi.org/10.1080/0307 5070309297

[43] Debowski S, Blake V, editors. The developmental needs of higher education academic leaders in encouraging effective teaching and learning. Seeking Educational Excellence, Teaching and Learning Forum 2004; 2004: University of WA. 
[44] Aziz S, Mullins ME, Balzer WK, et al. Understanding the training needs of department chairs. Studies in Higher Education. 2005; 30(5): 571-93. https://doi.org/10.1080/03075070500249260

[45] Montez J. Developing an Instrument to Assess Higher Education Leadership. 2003.

[46] Yielder J, Codling A. Management and leadership in the contemporary university. Journal of higher education policy and management. 2004; 26(3): 315-28. https://doi.org/10.1080/1360080042 000290177

[47] Gmelch WH. The development of campus academic leaders. International Journal of Leadership and Change. 2013; 1(1): 7.

[48] Gmelch WH. The Call for Department Leaders. 2002.

[49] Burns JM. Leadership New York. NY: Harper and Row Publishers. 1978.

[50] Bass BM. Leadership and Performance beyond expectations. New York: Free Press; 1985.

[51] Bass BM, Avolio BJ. Transformational leadership and organizational culture. Public administration quarterly. 1993; 112-21.
[52] Dugan JP, Komives SR, Segar TC. College student capacity for socially responsible leadership: Understanding norms and influences of race, gender, and sexual orientation. NASPA Journal. 2008; 45(4): 475-500. https://doi .org/10.2202/0027-6014.2008

[53] Sarros JC, Cooper BK, Santora JC. Building a Climate for Innovation Through Transformational Leadership and Organizational Culture. 2008.

[54] Elrehail H, Emeagwali OL, Alsaad A, et al. The impact of Transformational and Authentic leadership on innovation in higher education: The contingent role of knowledge sharing. Telematics and Informatics. 2018; 35(1): 55-67. https://doi.org/10.1016/j.tele.2 017.09 .018

[55] Okçu V. Relation between Secondary School Administrators' Transformational and Transactional Leadership Style and Skills to Diversity Management in the School. Educational Sciences: Theory and Practice. 2014; 14(6): 2162-74.

[56] Leithwood K, Jantzi D. A review of transformational school leadership research 1996-2005. Leadership and policy in schools. 2005; 4(3): 177-99. https://doi.org/10.1080/1570076050024476 9 